\title{
Rare bacterial isolates causing bloodstream infections in Ethiopian patients with cancer

Balew Arega ${ }^{1,2}$, Yimtubezinash Wolde-Amanuel ${ }^{2}$, Kelemework Adane ${ }^{3 *}$, Ezra Belay ${ }^{4}$, Abdulaziz Abubeker $^{5}$ and Daniel Asrat ${ }^{2}$

\begin{abstract}
Background: In recent years, saprophytic bacteria have been emerging as potential human pathogens causing life-threatening infections in patients with malignancies. However, evidence is lacking concerning such bacteria, particularly in sub-Saharan countries. This study was designed to determine the spectrum and drug resistance profile of the rare bacterial pathogens causing bloodstream infections (BSIs) in febrile cancer patients at a referral hospital in Ethiopia.
\end{abstract}

Methods: Between December 2011 and June 2012, blood samples were collected from 107 patients with cancer in Tikur Anbessa hospital. Culturing was performed using the blood culture bottles and solid media and the microorganisms were identified using the gram staining and APINE identification kits (Biomerieux, France). The disk diffusion method was used for the antimicrobial susceptibility testing.

Results: Overall, 13 (12.2\%) rare human pathogens were isolated from 107 adult febrile cancer patients investigated. Aeromonas hydrophilia species (a fermentative gram-negative rod) was the predominant isolate, 30.8\% (4/13), followed by Chryseomonas luteola 15.4\% (2/13), Sphignomonas poucimobilis 15.4\% (2/13), and Pseudomonas fluorescens 15.4\% (2/13). Of the nine isolates tested for a nine set of antibiotics, $89 \%$ were resistant to amoxicillin-clavulanic acid, ampicillin, and trimethoprim-sulphamethoxazole.

Conclusions: This study revealed the emergence of saprophytic bacteria as potential drug-resistant nosocomial pathogens in Ethiopian patients with cancer. As these pathogens are ubiquitous in the environment, infection prevention actions should be strengthened in the hospital and early diagnosis and treatment with appropriate antibiotics are warranted for those already infected.

Keywords: Bloodstream infections, Cancer patients, Drug resistance, Ethiopia, Rare bacteria

\section{Background}

Patients with cancer are at a high risk of infection and often the focus of the infection is not apparent. Bloodstream infections (BSIs) have been the leading complications in such patients $[1,2]$. In adult patients with malignancies, the crude mortality rates of BSIs range from $18 \%-42 \%[3,4]$. A variety of factors including frequent hospitalization, exposure to invasive procedures, use of broad-spectrum antibiotics and chemotherapy make cancer patients more susceptible to BSIs $[1,5]$. Chemotherapy renders cancer patients to be neutropenic

\footnotetext{
* Correspondence: ingoldmlt@gmail.com

${ }^{3}$ Department of Microbiology and Immunology, College of Health Sciences, Mekelle University, P.O.Box 1872, Mekelle, Ethiopia

Full list of author information is available at the end of the article
}

making them more susceptible to potentially lifethreatening BSIs [6, 7].

Bacteria are the primary causative agents of BSIs $[8,9]$. The gram-positive pathogens such as Staphylococcus aureus (prevalence of S. aureus ranging from 18\% - 35\%) $[10,11]$ and the gram-negative bacteria such as $E$. coil (13\% - 23.1\%), K. pneumoniae (4.6\% - 12\%), and/or P.aeruginosa $(6 \%-12.5 \%)[10,12,13]$ had been reported as the common pathogens causing BSIs in cancer patients. However, in recent years, saprophytic bacteria have been emerging as potential human pathogens causing lifethreatening infections in patients with malignancies. A case report from Delhi State Cancer Institute, for example, indicated that Aeromonas hydrophila, a saprophyte in the soil, caused a serious soft tissue infection in a woman with 
breast malignancy [14]. A study from Texas Children's Hospital isolated the plant pathogen Pantoea agglomerans from a blood culture of children [15]. Another study from Egypt had also reported the rare bacterial pathogen Chryseobacterium meningosepticum from blood cultures of patients with cancer [16].

The spectrum and drug resistance profile of the pathogens causing BSIs in patients with cancer have been reported to show significant fluctuations in different geographical areas and time points $[8,17]$. Data regarding the emerging saprophytic potential nosocomial pathogens is limited, particularly in sub-Saharan countries, despite the escalating burden of cancer. This study therefore aimed at determining the spectrum and drug resistance profile of the rare bacterial pathogens causing BSIs in febrile cancer patients at a referral hospital in Ethiopia.

\section{Methods}

\section{Study setting, design, and populations}

This cross-sectional study was conducted at Tikur Anbessa (Black Lion) referral teaching hospital in Addis Ababa, Ethiopia between December 2011 and June 2012. Tikur Anbessa Hospital is the largest hospital in Ethiopia and is a referral site for patients from all parts of the country. To date, this hospital is the only hospital providing cancer chemotherapy and radiotherapy service in Ethiopia. Cancer patients attending the hospital were our study populations. Providing written informed consent, being an age of $>18$ years and not being under antibiotic treatment during the study time were the inclusion criteria for this study. All inpatient and outpatient adult febrile cancer patients $(n=107)$ attending the Internal Medicine Department and Oncology-Radiotherapy Center of the hospital during the study period were included in the study conveniently.

\section{Specimen collection}

From each patient included in the study, venous blood was drawn aseptically. Two sets (one-bottle set) of $10 \mathrm{ml}$ for each patient were collected within 24 hours. Then, we poured blood samples into the blood-culture bottles and we incubated them aerobically at $37{ }^{\circ} \mathrm{C}$. We inspected these cultures daily for up to 7 days. Sociodemographic and other relevant data were also collected using structured questionnaire.

\section{Blood culture and identification}

We performed gram staining for broths that showed visible growth (as evidenced by the appearance of turbidity, growing colonies on top of the red cells ('cotton balls'), hemolysis, and /or gas bubbles). If growth was not detected within 24-hours, we undertook blind sub- culturing to recover pathogenic microorganisms. For bottles that did not show growth until 7 days, we performed terminal sub-culturing. Preliminary identification of the pathogens from the tubes that showed growth was done by gram staining.

Then, we sub-cultured the organisms on Blood agar, Chocolate agar, and MacConkey agar. We incubated these cultures aerobically at $37^{\circ} \mathrm{C}$ and growth was inspected for up to 24-48 hours. We used APINE identification kits (Biomerieux, France) to identify the non-fermentative gram-negative bacilli.

\section{Antimicrobial susceptibility testing}

We used the disk diffusion method for antimicrobial susceptibility testing following standard operating procedures. We prepared suspensions equivalent to a 0.5 McFarland standard by mixing 3-5 bacterial colonies from a pure culture with $5 \mathrm{ml}$ of saline. We then distributed the bacterial suspension evenly over the entire surface of MuellerHinton agar using a sterile cotton swab. The inoculated Muller-Hinton plates were left at room temperature for 3-5 minutes to dry and a nine set of antibiotic discs (Oxoid) were dispensed on the surface of each plate. The antibiotics used included amoxicillin-clavulanate (AMC) $(30 \mu \mathrm{g})$, chloramphenicol (C) (30 $\mu \mathrm{g})$, tetracycline (TTC) (30 $\mu \mathrm{g})$, trimethoprim-sulphamethoxazole (SXT) $(25 \mu \mathrm{g})$, ceftriaxone (CRO) $(30 \mu \mathrm{g})$, ampicillin (AMP) $(10 \mu \mathrm{g})$, nalidixic acid (NA) $(30 \mu \mathrm{g})$, gentamicin $(\mathrm{CN})(10 \mu \mathrm{g})$, and ciprofloxacin (CIP) $(5 \mu \mathrm{g})$. After incubation of the plates at $37^{\circ} \mathrm{C}$ for $24-$ 48 hours, we measured the diameters of the zone of inhibition to the nearest millimeter using a caliper. The isolates were then classified as sensitive, intermediate, and resistant according to the standardized table supplied by the Clinical Laboratory Standard Institute (CLSI). E. coli (ATCC-25922) and P.aeruginosa (ATCC-27853) were used as standard reference strains for quality control of the culture and antimicrobial susceptibility testing.

\section{Data analysis}

Data were entered using Epi Data entry version 3.1 software and analyzed using SPSS version 16. Descriptive statistics was used to depict the frequencies and proportions.

\section{Results \\ Patient profiles}

The study population has been previously described (in press). Briefly, of 107 adult febrile cancer patients enrolled, 52 (48.6\%) were males and 55 (51.4\%) females with a mean age of $35.5 \pm 14.64$ years. The majority of the study participants, 81 (75.7\%), suffered from leukemia and 56 (52.3\%) were neutropenic. More than half of the neutropenic patients were with leukemia. Seventy-six $(71 \%)$ of them had taken cancer therapy in which all received chemotherapy; none had received 
radiation therapy. About 57\% (61/107) had received antibiotics previously of which $64 \%$ (39/61) received ceftriaxone, 18\% (11/61) ceftriaxone, and vancomycin and the remaining 18\% (11/61) received ceftriaxone, vancomycin, and ciprofloxacin. None of the 107 patients investigated had either central intravenous device or indwelling intravenous devices during our investigation, but $76 \%$ (81/107) had total parenteral nutrition (TPN) devices.

\section{Bacterial isolates and their drug susceptibility pattern}

Of 107 adult febrile cancer patients investigated for BSIs, 71 bacterial pathogens were isolated of which 13 (18.3\%) were rare human pathogens. The characteristics and drug resistance profile of other pathogens have been previously described (in press). Out of the 13 rare bacterial pathogens, the majority $30.8 \%$ (4/13) were Aeromonas hydrophilia species (a fermentative gram-negative rod). Chryseomonas luteola, Sphignomonas poucimobilis, and Pseudomonas fluorescens each accounted two isolates while Chryseobacterium meningosepticum, Pantoea agglomerans, and Serratia ficaria accounted one isolate for each. The antimicrobial susceptibility results were available for nine of the $13(69.2 \%)$ isolates. Eighty-nine percent of these isolates were resistant to amoxicillin-clavulanic acid, ampicillin, and trimethoprim-sulphamethoxazole (Table 1).

\section{Discussion}

This study is the first to describe the rare bacterial isolates as causes of BSIs in Ethiopian patients with cancer. The fermentative gram-negative rod, Aeromonas hydrophilia species, was the most predominant isolate of the rare bacteria isolated. Previous studies from Egypt had also reported this pathogen as an agent of BSIs in patients with hematological malignancy $[18,19]$. Aeromonas species are widely distributed in the aquatic environment and patients acquire infection by oral consumption or direct contact with contaminated water or seafood [20]. Aeromonas may cause serious fatal infections such as hepatobiliary infection, invasive skin and soft tissue infections, primary bacteremia, burn infections, pleuropulmonary infection, meningitis and endocarditis in the immunocompromised patient [21, 22]. Though Aeromonas isolates are susceptible to a broad range of antibiotics, some species may produce beta-lactamase which makes them resistant to ampicillin and first-generation cephalosporins [23]. In this study, all the four isolates were resistant to amoxicillinclavulanic acid, ampicillin, and trimethoprimsulphamethoxazole suggesting the emergence of this saprophytic pathogen as a drug resistant potential nosocomial pathogen in Ethiopia.

Chryseomonas luteola, a saprophyte found in the soil and water, has only rarely been reported as a human bacterial pathogen [24, 25]. In a case report from a Moroccan University Hospital, this bacterium was indicated causing serious infection in a newborn with a respiratory failure [24]. In the current study, we isolated two Chryseomonas luteola pathogens from neutropenic patients with non-Hodgkin lymphoma. In the previous reports, Chryseomonas luteola isolates showed variable sensitivity to ampicillin,

Table 1 Susceptibility patterns of the rare bacteria isolated from blood cultures of febrile cancer patients at Tikur Anbessa specialized hospital, Addis Ababa, Ethiopia; December 2011 and June 2012

\begin{tabular}{|c|c|c|c|c|c|c|c|c|c|c|}
\hline \multirow[b]{2}{*}{ Organisms } & \multicolumn{10}{|c|}{ Antimicrobial drugs, n (\%) } \\
\hline & & AMC & AMP & C & CRO & SXT & $T T C$ & CIP & NA & $\mathrm{CN}$ \\
\hline \multirow[t]{3}{*}{ Aeromonas hydrophilia $(n=4)$} & $\mathrm{S}$ & - & - & $1(25)$ & $1(25)$ & - & - & $3(75)$ & $2(50)$ & $4(100)$ \\
\hline & । & - & - & $1(25)$ & - & - & $1(25)$ & - & - & - \\
\hline & $\mathrm{R}$ & $4(100)$ & $4(100)$ & $2(50)$ & $3(75)$ & $4(100)$ & $3(75)$ & $1(25)$ & $2(50)$ & - \\
\hline \multirow[t]{3}{*}{ Chryseomonas luteola $(n=2)$} & $S$ & - & - & - & - & - & $2(100)$ & $2(100)$ & $2(100)$ & $2(100)$ \\
\hline & । & - & - & - & - & - & - & - & - & \\
\hline & $\mathrm{R}$ & $2(100)$ & $2(100)$ & $2(100)$ & $2(100)$ & $2(100)$ & - & - & - & - \\
\hline \multirow[t]{3}{*}{ Pseudomonas fluorescens $(n=2)$} & S & - & - & $1(50)$ & $2(100)$ & & $1(50)$ & $1(50)$ & $1(50)$ & $2(100)$ \\
\hline & । & - & - & - & - & - & - & - & - & - \\
\hline & $\mathrm{R}$ & $2(100)$ & $2(100)$ & $1(50)$ & - & $2(100)$ & $1(50)$ & $1(50)$ & $1(50)$ & - \\
\hline \multirow[t]{3}{*}{ Serracia ficaria $(n=1)$} & $S$ & $1(100)$ & $1(100)$ & 1 (100) & - & 1 (100) & 1 (100) & 1 (100) & - & - \\
\hline & 1 & - & - & - & - & - & - & - & - & \\
\hline & $R$ & - & - & - & - & - & 1 (100) & - & - & 1 (100) \\
\hline \multirow[t]{3}{*}{ Total $(n=9)$} & $\mathrm{S}$ & $1(11.1)$ & $1(11.1)$ & $3(33.3)$ & & $1(11.1)$ & $3(33.3)$ & 7 (77.8) & $5(62.5)^{a}$ & 8 (88.9) \\
\hline & 1 & - & - & 1 (11.1) & & - & 1 (11.1 & - & - & \\
\hline & $R$ & 8 (88.9) & 8 (88.9) & $5(55.6)$ & & 8 (88.9) & $5(55.5)$ & $2(22.2)$ & $3(37.5)^{\mathbf{a}}$ & 1 (11.1) \\
\hline
\end{tabular}

${ }^{a}=$ the denominator is 8,5 Sensitive, I Intermediate, $R$ Resistant, AMC Amoxicillin-clavulanic acid, AMP Ampicillin, C Chloramphenicol, CRO Ceftriaxone, SXT Trimethoprim-sulphamethoxazole, TTC Teteracycline, CIP Ciprofloxacin GN Gentamycin, NA Nalidixic acid 
tetracycline, and co-trimoxazole. In this study, both isolates were resistant to five of the nine antibiotics tested including amoxicillin-clavulanic acid, ampicillin, chloramphenicol, ceftriaxone, and trimethoprim-sulphamethoxazole. This also suggests the emergence of this bacterium as a potential nosocomial pathogen in Ethiopia.

Chryseobacterium meningosepticum was isolated from a blood culture of a leukemic patient. This bacterium was already defined as etiology of bloodstream infection among cancer patients by the Infectious Diseases Society of America [26]. A study from Egypt had also reported this bacterium from blood cultures of patients with cancer [16]. Chryseobacterium meningosepticum is found in soil and can survive in chlorine-treated municipal water supplies [27] and could colonize patients via contaminated medical devices involving fluids (respirators, intubation tubes, incubators for newborns, ice chests, syringes, intravascular catheters, etc) $[28,29]$ and cause severe infections in immunocompromised people and in children [16, 28].

Two isolates of Sphignomonas poucimobilis were also observed in this study; one from a 40-year-old female patient with acute leukemia and the other from a 24year-old female patient with chronic lymphocytic leukemia. These non-fermenting gram-negative bacilli create a significant problem in clinical settings, being the most widespread cause of nosocomial infections. They are opportunistic pathogens that take advantage of underlying conditions and diseases [30]. According to a review of the case reports by Lin et al, about 42 isolates of S.poucimobilis were indicated as agents of BSIs in cancer patients (mostly in patients with hematological malignancy) [30]. The existence of this bacterium in our setting could pose a challenge in managing and treating patients appropriately as standard methods to undertake antibiotic susceptibility testing are not on hand for this pathogen [30].

Pantoea agglomerans, a very a rare fermentative gramnegative pathogen, was also isolated in our study as an agent of BSIs in patients with acute myeloid leukemia. Previously, this pathogen was isolated from patients with hematological malignancy in Belgium [31]. Pantoea agglomerans is a plant pathogen widely distributed in the soil [32]. A review of case reports indicated that P.agglomerans was mostly associated with penetrating trauma by vegetative material and catheter-related bacteremia in immunocompromised patients and in children in the hospital [15].

Serratia ficaria has been isolated from human clinical samples in rare instances [33]. Although its pathogenicity was always questionable, S. ficaria was later found to be able to cause severe infections (septicemia) or deep suppurations such as gallbladder empyema [34]. Thus, $S$. ficaria is an opportunistic pathogen responsible for colonization or serious infections in compromised patients. In this study, we isolated this organism from a 24-year-old female patient with acute lymphocytic leukemia. Another study in France also isolated Serratia ficaria from a blood of 83-year-old adenocarcinoma patient [34]. Other case reports [33, 35] also reported this bacterium from a blood culture of patients with underlying disease other than neoplasm. In previous reports, S. ficaria was usually susceptible to numerous antibiotics but always resistant to cephalothin (cefazolin was the prophylactic antibiotic in the present case) [34]. In our study, the $S$. ficaria isolate was susceptible to seven of the nine antibiotics tested while it was resistant to teteracycline and nalidixic acid. We didn't test it against cephalothin (cefazolin).

We also recovered two isolates of Pseudomonas fluorescens from blood cultures of male febrile neutropenic patients with hematological malignancy. Previously, $P$. fluorescens was reported from a bone marrow transplant patients with hematological malignancies, who became colonized with the organism from a contaminated water dispenser that supplied bottled natural spring water in a hospital [36]. The case holds also true in our setting where the patients didn't have adequate access to clean water supply. A previous study showed that $P$. fluorescens strains isolated from cancer patients were susceptible to gentamicin, neomycin, tetracyclines, polymyxin $\mathrm{B}$, and colistin and resistant to chloramphenicol, ampicillin, and narrow-spectrum cephalosporin [37, 38]. In the current study, both of our isolates were resistant to amoxicillinclavulanic acid, ampicillin, and trimethoprimsulphamethoxazole and one of the strains were resistant to teteracycline, ciprofloxacillin and nalidixic acid. This is of some concern because these classes of antibiotics are commonly recommended for the management of neutropenic sepsis in hematological malignancies.

To mention some of the limitations: first we used only aerobic culture techniques; anaerobic microorganisms that might have been contributing for BSIs were not defined. The fact that we took only blood sample might also have limited the range of bacterial pathogens to be isolated.

\section{Conclusions}

This study revealed the emergence of saprophytic bacteria as potential drug-resistant nosocomial pathogens in Ethiopian patients with cancer. The majority of the isolates were resistant to the commonly used chemotherapic antibiotics imposing a challenge to the health care program. As these pathogens are ubiquitous in the environment, infection prevention actions should be strengthened in the hospital and early diagnosis and treatment with appropriate antibiotics are warranted for those already infected. 


\section{Acknowledgments}

The authors are thankful to all staff members of the Internal Medicine and Oncology-radiotherapy center of Tikur Anbesa Hospital for their collaboration during the data collection. We would also like to thank the School of Graduate study of Addis Ababa University for financing this project.

\section{Funding}

This study was financially supported by the School of Graduate Studies of Addis Ababa University. The funder had no role in study design, data collection, and analysis, decision to publish, or preparation of the manuscript.

\section{Availability of data and materials}

Please contact the author for data requests.

\section{Authors' contributions}

$B A, D A$, and $Y W$ were involved in the study conception and design, culturing and drug susceptibility testing, data analysis and drafting of the manuscript. KA was involved in the data analysis, drafting and writing up of the manuscript and correction of the comments. EB involved in writing up of the manuscript. All authors have read and approved the final version of the manuscript.

\section{Ethics approval and consent to participate}

The Ethical Review Committee (ERC) of the Department of Medical Microbiology, Immunology and Parasitology of Addis Ababa University approved the study. All participants were enrolled after they provided us a written informed consent. For those patients that were critically ill and were unable to give a response, we received consent from their family members (caregivers). We also had immediately reported the results of culture and susceptibility testing to physicians so as to guide the treatment and management of the patients.

\section{Consent for publication}

Not applicable.

\section{Competing interests}

The authors declare that there is no any competing interest.

\section{Publisher's Note}

Springer Nature remains neutral with regard to jurisdictional claims in published maps and institutional affiliations.

\section{Author details}

${ }^{1}$ College of Health Sciences, Debremarkos University, P.O.Box 269, Debremarkos, Ethiopia. ${ }^{2}$ Department of Microbiology, Immunology \& Parasitology, School of Medicine, College of Health Sciences, Addis Ababa University, Churchill Avenue, P.O. Box 9086, Addis Ababa, Ethiopia. ${ }^{3}$ Department of Microbiology and Immunology, College of Health Sciences, Mekelle University, P.O.Box 1872, Mekelle, Ethiopia. ${ }^{4}$ Department Medical Biochemistry, College of Health Sciences, Mekelle University, P.O.Box 1872. Mekelle, Ethiopia. ${ }^{5}$ Department of Internal Medicine, School of Medicine, College of Health Sciences, Addis Ababa University, Churchill Avenue, P.O. Box 9086, Addis Ababa, Ethiopia.

\section{Received: 17 April 2017 Accepted: 5 July 2017}

\section{Published online: 11 July 2017}

\section{References}

1. Walshe LJ, Malak SF, Eagan J, Sepkowitz KA. Complication rates among cancer patients with peripherally inserted central catheters. Journal of Clinical Oncology. 2002:20(15):3276-81.

2. Wisplinghoff $H$, Bischoff $T$, Tallent $S M$, Seifert $H$, Wenzel RP, Edmond MB. Nosocomial bloodstream infections in US hospitals: analysis of 24,179 cases from a prospective nationwide surveillance study. Clinical Infectious Diseases. 2004;39(3):309-17.

3. Fayyaz M, Mirza IA, Ikram A, Hussain A, Ghafoor T, Shujat U. Pathogens Causing Blood Stream Infections and their Drug Susceptibility Profile in Immunocompromised Patients. Journal of the College of Physicians and Surgeons Pakistan. 2013;23(12):848-51.

4. Butt T, Afzal RK, Ahmad RN, Salman M, Mahmood A, Anwar M. Bloodstream infections in febrile neutropenic patients: bacterial spectrum and antimicrobial susceptibility pattern. J Ayub Med Coll Abbottabad. 2004;16(1):18-22.
5. Leibovici L, Shraga I, Drucker M, Konigsberger H, Samra Z, Pitlik S. The benefit of appropriate empirical antibiotic treatment in patients with bloodstream infection. JOURNAL OF INTERNAL MEDICINE-OXFORD-. 1998;244: 379-86.

6. Crawford J, Dale DC, Lyman GH. Chemotherapy-induced neutropenia. Cancer. 2004;100(2):228-37.

7. Cebon J, Layton JE, Maher D, Morstyn G. Endogenous hemopoietic growth factors in neutropenia and infection. British journal of hematology. 1994; 86(2):265-74.

8. Ramphal R. Changes in the etiology of bacteremia in febrile neutropenic patients and the susceptibilities of the currently isolated pathogens. Clinical infectious diseases. 2004;39(Supplement 1):S25-31.

9. Rolston KV, Bodey GP. Bacterial Infections in Cancer Patients. Cancer Supportive Care: Advances in Therapeutic Strategies. 2008;6:73.

10. Mutnick AH, Kirby JT, Jones RN. CANCER resistance surveillance program: initial results from hematology-oncology centers in North America. Annals of Pharmacotherapy. 2003:37(1):47-56.

11. Nejad ZE, Ghafouri E, Farahmandi-Nia Z, Kalantari B, Safari F. Isolation, identification, and profile of antibiotic resistance of bacteria in patients with cancer. Iranian Journal of Medical Sciences. 2015;35(2):109-15.

12. Chen C-Y, Tang J-L, Hsueh P-R, Yao M, Huang S-Y, Chen Y-C, et al. Trends and antimicrobial resistance of pathogens causing bloodstream infections among febrile neutropenic adults with hematological malignancy. Journal of the Formosan Medical Association=. Taiwan yi zhi. 2004;103(7):526-32.

13. Zahid KF, Hafeez H, Afzal A. Bacterial spectrum and susceptibility patterns of pathogens in adult febrile neutropenic patients: a comparison between two time periods. J Ayub Med Coll Abbottabad. 2009;21(4):146-9.

14. Baruah FK, Ahmed NH, Grover RK. Surgical site infection caused by Aeromonas hydrophilia in a patient with underlying malignancy. Journal of clinical and diagnostic research: JCDR. 2015;9(1):DD01.

15. Cruz AT, Cazacu AC, Allen CH. Pantoea agglomerans, a plant pathogen causing human disease. Journal of Clinical Microbiology. 2007;45(6):1989-92.

16. El-Mahallawy HA, El-Wakil M, Moneer MM, Shalaby L. Antibiotic resistance is associated with longer bacteremic episodes and worse outcome in febrile neutropenic children with cancer. Pediatric blood \& cancer. 2011;57(2):283-8.

17. Montassier E, Batard E, Gastinne T, Potel G, de La Cochetière M. Recent changes in bacteremia in patients with cancer: a systematic review of epidemiology and antibiotic resistance. European journal of clinical microbiology \& infectious diseases. 2013;32(7):841-50.

18. Baskaran ND, Gan GG, Adeeba K, Sam I-C. Bacteremia in patients with febrile neutropenia after chemotherapy at a university medical center in Malaysia. International Journal of Infectious Diseases. 2007;11(6):513-7.

19. Ashour HM, El-Sharif A. Microbial spectrum and antibiotic susceptibility profile of gram-positive aerobic bacteria isolated from cancer patients. Journal of Clinical Oncology. 2007;25(36):5763-9.

20. Igbinosa $\mathrm{IH}$, Igumbor EU, Aghdasi F, Tom M, Okoh Al. Emerging Aeromonas species infections and their significance in public health. The Scientific World Journal. 2012;2012

21. Okumura K, Shoji F, Yoshida M, Mizuta A, Makino I, Higashi H. Severe sepsis caused by Aeromonas hydrophila in a patient using tocilizumab: a case report. J Med Case Rep. 2011;5:499.

22. Janda JM, Abbott SL. The genus Aeromonas: taxonomy, pathogenicity, and infection. Clinical microbiology reviews. 2010;23(1):35-73.

23. Medeiros AA. Evolution and dissemination of $\beta$-lactamases accelerated by generations of $\beta$-lactam antibiotics. Clinical Infectious Diseases. 1997; 24(Supplement 1):S19-45.

24. Chihab W, Alaoui AS, Amar M. Chryseomonas luteola identified as the source of serious infections in a Moroccan University Hospital. Journal of clinical microbiology. 2004;42(4):1837-9.

25. Kostman JR, Solomon F, Fekete T. Infections with Chryseomonas luteola (CDC group Ve-1) and Flavimonas oryzihabitans (CDC group Ve-2) in neurosurgical patients. Review of Infectious Diseases. 1991;13(2):233-6.

26. Hugues W, Armstrong D, Bodey G, Bow E, Brown A, Calandra T. Guidelines for the use of antimicrobial agents in neutropenic patients with cancer. Clin Infect Dis. 2002;34(6):730-51.

27. Bloch KC, Nadarajah R, Jacobs R. Chryseobacterium meningosepticum: An Emerging Pathogen Among Immunocompromised Adults Report of 6 Cases and Literature Review. Medicine. 1997:76(1):30-41.

28. Güngör S, Özen M, Akinci A, Durmaz R. A Chryseobacterium meningosepticum outbreak in a neonatal ward. Infection Control \& Hospital Epidemiology. 2003;24(08):613-7. 
29. Vandamme P, Bernardet J-F, Segers P, Kersters K, Holmes B. NOTES: New Perspectives in the Classification of the Flavobacteria: Description of Chryseobacterium gen. nov., Bergeyella gen. nov., and Empedobacter nom. rev. International Journal of Systematic and Evolutionary Microbiology. 1994;44(4):827-31.

30. Lin J-N, Lai C-H, Chen Y-H, Lin H-L, Huang C-K, Chen W-F, et al. Sphingomonas paucimobilis bacteremia in humans: 16 case reports and a literature review. Journal of Microbiology, Immunology and Infection. 2010; 43(1):35-42.

31. Mebis J, Jansens H, Minalu G, Molenberghs G, Schroyens W, Gadisseur A et al. Long-term epidemiology of bacterial susceptibility profiles in adults suffering from febrile neutropenia with hematologic malignancy after antibiotic change. Infection and drug resistance. 2010;3:53.

32. Andersson A, Weiss N, Rainey F, Salkinoja-Salonen M. Dust-borne bacteria in animal sheds, schools and children's day care centres. Journal of applied microbiology. 1999:86(4):622-34

33. Anahory T, Darbas $H$, Ongaro O, Jean-Pierre H, Mion P. Serratia ficaria: a misidentified or unidentified rare cause of human infections in fig tree culture zones. Journal of clinical microbiology. 1998;36(11):3266-72.

34. Darbas $\mathrm{H}$, Jean-Pierre $\mathrm{H}$, Paillisson J. Case report and review of septicemia due to Serratia ficaria. Journal of clinical microbiology. 1994;32(9):2285-8.

35. Gill V, Farmer J, Grimont P, Asbury M, McIntosh C. Serratia ficaria isolated from a human clinical specimen. Journal of clinical microbiology. 1981;14(2):234-6.

36. Wong V, Levi K, Baddal B, Turton J, Boswell TC. Spread of Pseudomonas fluorescens due to contaminated drinking water in a bone marrow transplant unit. Journal of clinical microbiology. 2011;49(6):2093-6.

37. Moody MR, Young VM, Kenton DM. In vitro antibiotic susceptibility of pseudomonads other than Pseudomonas aeruginosa recovered from cancer patients. Antimicrobial agents and chemotherapy. 1972;2(5):344-9.

38. Kenneth V, Rolston I. Infections in Cancer Patients with Solid Tumors: A Review. Infect Dis Ther. 2017;6(1):69-83.

\section{Submit your next manuscript to BioMed Central and we will help you at every step:}

- We accept pre-submission inquiries

- Our selector tool helps you to find the most relevant journal

- We provide round the clock customer support

- Convenient online submission

- Thorough peer review

- Inclusion in PubMed and all major indexing services

- Maximum visibility for your research

Submit your manuscript at www biomedcentral.com/submit

) Biomed Central 